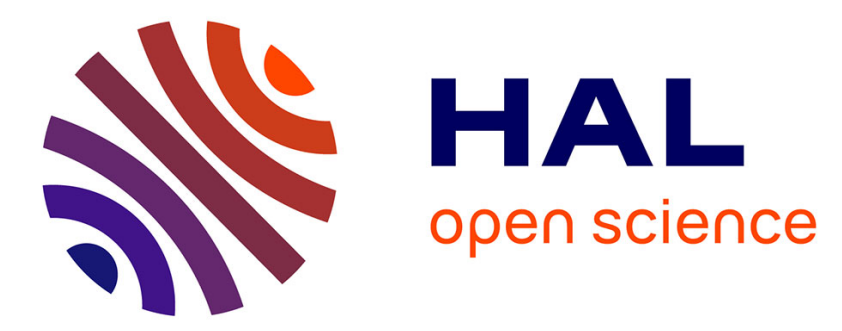

\title{
Adoption of low-cost energy efficiency measures in the tertiary sector-An empirical analysis based on energy survey data
}

\author{
Barbara Schlomann, Joachim Schleich
}

\section{- To cite this version:}

Barbara Schlomann, Joachim Schleich. Adoption of low-cost energy efficiency measures in the tertiary sector-An empirical analysis based on energy survey data. Renewable and Sustainable Energy Reviews, 2015, 43, pp.1127 - 1133. 10.1016/j.rser.2014.11.089 . hal-01107719

\section{HAL Id: hal-01107719 \\ https://hal.science/hal-01107719}

Submitted on 21 Jan 2015

HAL is a multi-disciplinary open access archive for the deposit and dissemination of scientific research documents, whether they are published or not. The documents may come from teaching and research institutions in France or abroad, or from public or private research centers.
L'archive ouverte pluridisciplinaire HAL, est destinée au dépôt et à la diffusion de documents scientifiques de niveau recherche, publiés ou non, émanant des établissements d'enseignement et de recherche français ou étrangers, des laboratoires publics ou privés. 


\title{
Adoption of low-cost energy efficiency measures in the tertiary sector - an empirical analysis based on energy survey data
}

\author{
Barbara Schlomann ${ }^{\mathrm{a}}$, Joachim Schleich ${ }^{\mathrm{b}}$
}

a Corresponding author. Fraunhofer Institute for Systems and Innovation Research (ISI), Breslauer Strasse 48, 76139 Karlsruhe, Germany, e-mail: barbara.schlomann@isi.fraunhofer.de, phone: +49 721 6809136, fax: +49 7216809272

${ }^{\mathrm{b}}$ Fraunhofer Institute for Systems and Innovation Research (ISI), Breslauer Strasse 48, 76139 Karlsruhe, Germany and with Grenoble Ecole de Management, 12, rue Pierre Sémard, BP 127, 38003 Grenoble Cedex 01, France, e-mail: joachim.schleich@grenoble-em.com

\begin{abstract}
This paper empirically explores factors driving the adoption of low cost energy efficiency measures in the tertiary sector which mainly consists of public and private services, trade, commerce and some small industries. The measures considered include switching off installations or lighting, managing energy use, and routinely considering energy efficiency for new purchases. Our statistical analysis employs single and multivariate probit models relying on more than 1500 observations from a recent representative survey of the tertiary sector in Germany. The findings suggest that the landlord-tenant dilemma holds for the adoption of all low-cost energy efficiency measures considered. They further imply that financial incentives such as higher energy prices accelerate the diffusion of low-cost energy measures. Our findings also provide some evidence that knowledge transfer from the mother company to a subsidiary enhances the diffusion of low-cost energy efficiency measures. Likewise, public-sector organizations are more likely to adopt energy management. By and large though, sectoral heterogeneity appears to have little impact on the adoption of low-cost energy efficiency measures.
\end{abstract}

Keywords: Energy management; low-cost energy efficiency measures; tertiary sector. 


\section{Introduction}

Improving energy efficiency is typically considered to be the most cost-effective option to mitigate climate change, in particular in the short to medium run (e.g. IEA 2013). For the European Union, recent study results suggest that there is a cost-effective final energy savings potential of up to $40 \%$ by 2030 to which all energy consumption sectors need to contribute in different proportions. Accordingly, the largest energy efficiency potentials exist in the residential sector, but energy savings potentials in the industry and the tertiary sector are also substantial (Eichhammer 2013; Fraunhofer ISI et al. 2014)1.

The tertiary sector in Germany as it is defined here covers 32.8 million employees, hence accounting for around $80 \%$ of total employees. The final energy consumption of the sector amounted to $366 \mathrm{TWh}$ in 2011 , i.e. $15 \%$ of total final energy consumption in Germany. With a share of around $40 \%$, lighting it is the main electrical end-use in the tertiary sector (see Figure 1). Lighting offers a large energy savings potential which can be addressed both by technical (low-cost) and by organizational and behavioral measures (Fraunhofer ISI 2012). Other important end-uses for electricity in the tertiary sector are mechanical power, information and communication technologies (ICT) and process cooling. The application structure for fossil fuels (incl. district heat) is less differentiated; more than $70 \%$ of the final energy demand in the tertiary sector is accounted for by space heating followed by process heat with almost $15 \%$.

Thus, an enhanced understanding of the factors driving adoption of energy-efficiency measures is expected to provide guidance for better policy design. While there are many studies employing survey data to analyze the adoption of energy efficiency measures in households (Sardianou 2007, Nair et al. 2010, Mills and Schleich 2012, 2014, Astmarsson et al. 2013), data availability has only allowed few such studies for the industry sector (Thollander and Ottosson 2010, Abdelaziz et al. 2011, Stenqvist et al. 2011, Stenqvist 2012, Stenqvist and Nilsson 2012) and for the tertiary sector and SMEs (Jochem and Gruber 1990, Gruber and Brand 1991, Thollander et al. 2007, Schleich and Gruber 2008, Schleich 2009, Thollander and Dotzauer 2010, Cagno et al. 2010, Fleiter et al. 2012, Trianni and Cagno 2012, Trianni et al. 2013).

1 The tertiary sector is rather heterogeneous, mainly including public and private services, trade, commerce and some small industries. In the following, these sectors are only referred to as "tertiary sector". 


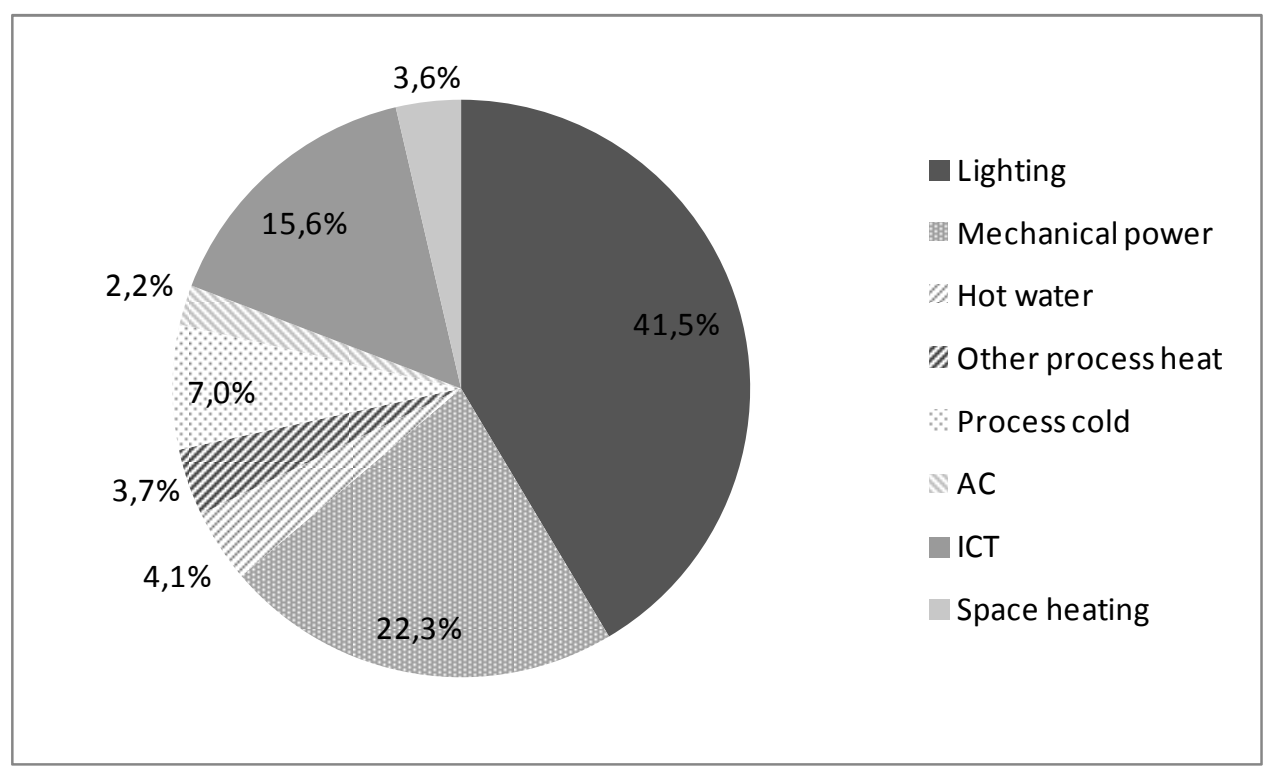

Fossil fuels (incl. district heat)

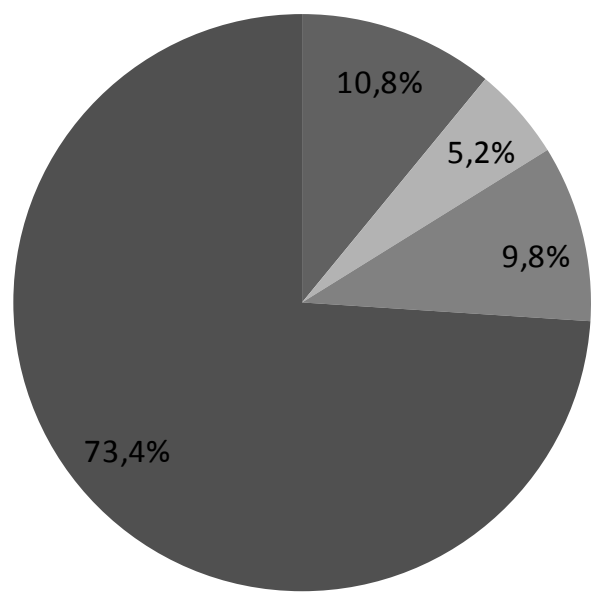

Mechanical power

Hot water

Other process heat

- Space heating

Source: Schlomann et al. 2013, 2014

Figure 1: Final energy consumption in the tertiary sector by end-uses [shares in \%]

The empirical literature analyzing the adoption of energy efficient technologies in the tertiary sector and in small and medium sized enterprises (SMEs) suggests that size matters: larger organizations are more likely to adopt energy efficiency measures (e.g. Aramyan et al., 2007, Schleich 2009, Trianni et al. 2013). In particular, larger organizations allow for economies of scale and also have more resources available, i.e. higher technological and financial know how. Therefore, larger organizations are also less likely to suffer from a lack of information (e.g. about energy use or technology availability) and other transaction costs, which have been identified as a major factor in organization's decision to adopt energy efficient technologies (e.g. Gruber and Brand 
1991, Ostertag 2003, Schleich and Gruber 2008, Schleich 2009). Larger organizations are generally also more innovative because they can spread the risk of technology adoption across a larger portfolio and may more easily acquire external funding (e.g. because they may more easily provide collateral). In general, most studies find capital availability (or lack thereof) to be an important factor for energy efficient technology adoption (Thollander et al. 2007, Fleiter et al. 2012, Trianni and Cagno 2012). Some studies (e.g. Schleich 2004) find that more energy intensive companies are more likely to adopt energy efficiency measures. For these organizations, energy efficiency is more likely to affect an organization's competitiveness, and to be of 'strategic' importance (Cooremans 2011).

Similarly, since higher energy prices improve the rate of return and shorten pay-back times of investments in energy efficiency, they tend to be associated with higher adoption rates (Velthuijsen 1993, Nagesha and Balachandra 2006). The effect of the form of company ownership on technology adoption has mainly been analyzed in the context of technology transfer to developing countries, e.g. via the Clean Development Mechanism (e.g. Dechezleprêtre et al. 2008). Thus, subsidiaries (of multinational companies) are typically associated with higher adoption rates. On the other hand, incentives to save energy costs at the subsidiary level are low if the mother organization appropriates the benefits (split-incentives problem). In comparison, several studies find that owning (rather than renting) a building increases organizations' propensity to adopt energy efficient technologies (Schleich and Gruber 2008). For rented buildings, the investment in an energy efficiency measures may not be able to fully appropriate the benefits. This split-incentive problem is also known as the landlord-tenant or user-investor dilemma. Finally, Sorrell et al. (2004) and Palm (2009) highlight the importance of social factors and organizational attributes (e.g. "energy culture") for the adoption of energy efficient technologies.

In general though, these studies have focused on medium- to high-cost energy efficiency measures. In this study we contribute to the existing empirical literature by exploring factors driving the adoption of low-cost energy efficiency measures such as controlling lighting, energy management measures or purchasing procedures. Our statistical analyses rely on data from a recent representative survey of the tertiary sector in Germany.

The paper is organized as follows: In Section 2 we provide a description of the basic survey together with descriptive statistics and the econometric model used in the analyses. The estimation results are presented in Section 3. In the concluding Section 4 , we interpret and discuss these results and derive implications for policy making. 


\section{Methodology}

\subsection{Survey methodology}

We base our analyses on data from a representative survey on energy consumption in the tertiary sector in Germany (Schlomann et al. 2013, 2014). A total of 2,131 companies and public institutions were interviewed personally (Computer Assisted Personal Interviews - CAPI) by experienced interviewers from $\mathrm{GfK}^{2}$. The addressees for the interviews were the main responsible for energy management in the respective company in order to ensure a high level of knowledge on energy consumption and energy efficiency measures in the firm. Data from 2,113 respondents could be used for our analyses. The interviews were conducted between July and November 2011. The survey on energy consumption was carried out for the $5^{\text {th }}$ time since 2001 , and is subject to strict quality control. In the survey, the tertiary sector was defined in the same way as in the German national energy balances (AGEB 2013) i.e. it includes all public and private services and trade, but also agriculture, construction and some small industrial enterprises. Because of its heterogeneity, the sector was broken down into 14 sub-sectors, 11 of which were covered by interviews (see Table 1). The sub-sectors were clustered and based on similar energy consumption patterns.

The complete survey questionnaire consists of three parts. The first part comprises general questions on the general structure of the companies involved (e.g. number of employees, floor space, organizational structure), and on economic and technical information on energy use (as e.g. total energy consumption and energy costs, energy consumption for different end-uses like space heating or lighting). The second part involves questions about energy management and measures to improve energy performance. The third part includes additional questions on the specific sub-sector. The analyses in this paper mainly employ information from the energy management part of the questionnaire and relate them to general and economic characteristic of the companies. The energy management section of the questionnaire includes first of all questions addressing the general attitude of the company towards energy efficiency and the undertaking of energy saving measures. In addition, the survey asked for concrete energy savings measures, which refer to a specific end-use, i.e. lighting, or organizational practices. 3

2 GfK is a market research company collecting market and consumer information in more than 100 countries worldwide (www.gfk.com).

3 The exact survey questions used in this analysis are available upon request from the authors. 
Table 1: Employment and energy consumption in the sub-sectors covered by the survey in the tertiary sector (in 2011)

\begin{tabular}{llll} 
Sub-sector & $\begin{array}{l}\text { Number of } \\
\text { interviews }\end{array}$ & $\begin{array}{l}\text { Number of } \\
\text { employees } \\
\text { [in 1000] }\end{array}$ & $\begin{array}{l}\text { Final energy } \\
\text { consumption } \\
\text { [in TWh] }\end{array}$ \\
\hline Construction & 171 & 2,428 & 15.4 \\
Offices & 467 & 13,294 & 86.0 \\
Small manufacturing & 216 & 924 & 11.5 \\
Retail trade & 458 & 5,479 & 60.3 \\
Hospitals/schools/pools & 212 & 2,707 & 45.0 \\
Hotels/restaurants & 247 & 3,983 & 62.8 \\
Food & 141 & 166 & 2.6 \\
Laundries & 35 & 53 & 1.0 \\
Agriculture & 104 & 642 & 44.2 \\
Horticulture & 18 & 195 & 4.7 \\
Textile & 44 & 858 & 3.9 \\
Others* & 0 & 2,029 & 28.2 \\
\hline Total tertiary & 2,113 & 32,758 & 365.6 \\
\hline
\end{tabular}

* The remaining sub-sector (mainly airports, military, street lighting) were only analyzed based on secondary data.

Source: Schlomann et al. 2013, 2014

\subsection{Econometric model}

The factors driving the adoption of energy-efficiency measures are explored econometrically. In this section, we present the dependent and explanatory variables.

\subsubsection{Dependent and explanatory variables}

In the energy management part of the questionnaire, respondents were asked to state whether they had adopted particular energy efficiency measures in their company. These items serve as dependent variables in our multivariate analyses and are further described in Table 2. A full set of dependent and explanatory variables was available for 1,528 observations.

Thus, all measures considered are rather low-cost measures. Lightoff is clearly related to electricity cost savings, while the other measures may also imply fuel cost savings. The set of explanatory variables available is described in Table 3. 
Table 2: $\quad$ Overview of dependent variables

\begin{tabular}{|c|c|}
\hline Name & Explanation \\
\hline switchoff & 1 , if energy-using installations are switched off whenever possible; otherwise 0 ; \\
\hline lightoff & 1 , if lighting only switched on when needed; otherwise 0 ; \\
\hline management & $\begin{array}{l}1 \text {, if energy management measures or energy controlling measures implemented; } \\
\text { otherwise 0; }\end{array}$ \\
\hline purchase & 1 , if energy efficiency is always considered for new purchases; otherwise 0 ; \\
\hline
\end{tabular}

Table 3: $\quad$ Overview of explanatory and control variables and expected sign

\begin{tabular}{llc} 
Name & Explanation & $\begin{array}{c}\text { Expected } \\
\text { sign }\end{array}$ \\
\hline powerprice & $\begin{array}{l}\text { in Euro/kWh calculated as the ratio of total electricity costs and total } \\
\text { electricity consumption; }\end{array}$ & + \\
energyintensity & total energy use (fuel and electricity) (in $\mathrm{MWh}$ ) per employee & + \\
floorspace & total floor space of organization (in $1000 \mathrm{~m}^{2}$ ) & + \\
employees & $\begin{array}{l}\text { total number of employees (including part time employees) (in } \\
\text { 1000) }\end{array}$ & + \\
rented & 1 , if buildings are (mostly) rented; otherwise 0; & + \\
subsidiary & 1, if organization is a subsidiary; otherwise 0; \\
rural & 1, if organization is located in rural area; 0; & + \\
\hline
\end{tabular}

Our choice of explanatory and other control variables is driven by the literature and also on data availability. Powerprice is supposed to reflect the economic incentive to adopt measures which reduce electricity use. Hence the coefficient of powerprice should have a positive sign for all four adoption decisions ${ }^{4}$. Similarly, energyintensity proxies the strategic importance of energy costs and should therefore exhibit a positive sign. Organizations with larger floorspace, exhibit higher energy consumption and are expected to have stronger economic incentives to adopt energy efficient measures, ceteris paribus. The number of employees is frequently used as a proxy for the size of an organization and is expected to have a positive effect on the adoption of energy efficiency measures. Rented is considered to reflect the landlord tenant problem, and should be negatively related with the dependent variables. For subsidiary, we leave it as an empirical question whether the knowledge spillover effect or the split incentive effect dominates. Finally, organizations in rural areas are less likely to benefit from knowledge spillovers from other organizations, and face a more difficult access to

4 Because of missing data on the expenditures for gas, coal and oil, prices for these fuels were not included in the analysis. 
information and know-how about energy-efficiency measures. Thus, rural should exhibit a negative sign in the multivariate analysis.

In addition, eleven dummies were included to control for heterogeneity across sectors. Table 4 provides descriptive statistics of the dependent and explanatory variables included in the subsequent econometric analysis. The data for the dependents variables appear in the first four rows. For example, the mean of 0.362 for management implies that $36.2 \%$ of the organizations in our sample had implemented energy management measures or energy controlling measures. Similarly, 0.013 for the sector dummy laundry means that laundry units account for $1.3 \%$ of the observations in our sample. Note that the means of the sector dummies add up to 1.

Table 4: $\quad$ Descriptive statistics of dependent and explanatory variables $(\mathrm{N}=1528)$

\begin{tabular}{|c|c|c|c|c|c|}
\hline Variable & Unit & Mean & Std. Dev. & Min. & Max \\
\hline switchoff & 0/1 dummy & 0.622 & 0.485 & 0 & 1 \\
\hline lightoff & 0/1 dummy & 0.750 & 0.433 & 0 & 1 \\
\hline management & $0 / 1$ dummy & 0.362 & 0.481 & 0 & 1 \\
\hline purchase & 0/1 dummy & 0.662 & 0.473 & 0 & 1 \\
\hline powerprice & Euro/kWh & 0.205 & 0.035 & 0.06 & 0.29 \\
\hline fuel intensity & MWh/employee & 14.78 & 27.86 & 0.66 & 896 \\
\hline floorsize & $1000 \mathrm{~m}^{2}$ & 1.613 & 5.534 & 0.02 & 140 \\
\hline employees & Number (in 1000) & 20.88 & 68.73 & 1 & 1150 \\
\hline rented & $0 / 1$ dummy & 0.448 & 0.497 & 0 & 1 \\
\hline subsidiary & 0/1 dummy & 0.181 & 0.385 & 0 & 1 \\
\hline rural & $0 / 1$ dummy & 0.367 & 0.482 & 0 & 1 \\
\hline construction & 0/1 dummy & 0.082 & 0.274 & 0 & 1 \\
\hline offices & 0/1 dummy & 0.219 & 0.413 & 0 & 1 \\
\hline small manufacturing & 0/1 dummy & 0.104 & 0.305 & 0 & 1 \\
\hline retail trade & 0/1 dummy & 0.215 & 0.411 & 0 & 1 \\
\hline hospitals/schools/pools & 0/1 dummy & 0.088 & 0.283 & 0 & 1 \\
\hline hotels/restaurants & 0/1 dummy & 0.130 & 0.337 & 0 & 1 \\
\hline food & 0/1 dummy & 0.070 & 0.255 & 0 & 1 \\
\hline laundries & 0/1 dummy & 0.013 & 0.114 & 0 & 1 \\
\hline agriculture & 0/1 dummy & 0.046 & 0.211 & 0 & 1 \\
\hline horticulture & 0/1 dummy & 0.009 & 0.095 & 0 & 1 \\
\hline textile & 0/1 dummy & 0.024 & 0.152 & 0 & 1 \\
\hline
\end{tabular}

\subsubsection{Econometric Methodology}

The dependent variables are all binary, and standard univariate probit models could be applied to estimate the adoption of the energy efficiency measures. However, to allow 
for the possibility that organizations do not adopt these measures individually, we estimate a multivariate probit model instead, thus accounting for possible correlations between the dependent variables through the corresponding error terms. Unless these correlations are zero, parameter estimates from univariate probit models are biased and inconsistent (e.g. Greene 2012). We use the statistical software package STATA 13 to estimate the four probit models jointly. For comparison, we also estimate individual univariat probit models. To prevent singularity of the regressor matrix we do not include a dummy for the last sub-sector textile.

\section{Results}

For the multivariate probit model results appear in Table 5. Heteroskedasticity-robust standard errors are shown in parenthesis below parameter estimates. To save space, the findings for the individual probit models are presented in the Appendix Table A.1. We find that the correlation is positive between all equations, and statistically significant (at $\mathrm{p}<0.01$ ) for five of the six correlations (only for management and lightoff, correlation was found to be zero). 5 Hence, as suspected, decisions to adopt the energy efficiency measures considered do not tend to be independent 6 . However, comparing the results in Table 5 and Table A.1 suggests that the parameter estimates (and the significance levels) hardly differ between the multivariate probit model and the univariate probit models (see Appendix A, Table A.1). Thus, the bias from running individual probits appears to be rather marginal.

The price of electricity (powerprice) was found to be statistically significant $(p<0.05)$ for lightoff only, also exhibiting the expected positive sign. Powerprice is not statistically significant for any other low-cost measures considered. For lightoff we also calculate the average marginal effect of powerprice. Accordingly, an increase in the power price by $10 €$ cts (i.e. an increase by almost $50 \%$ compared to the mean) increases the probability that lighting is only switched on when needed by 7 percentage points. Since the mean for lightoff is 0.75 (see Table 4), this corresponds to an increase by about $9 \%$. Hence, while statistically significant, the effect of the electricity price on lightoff is rather limited.

5 All results which are not shown here to save space are available from the authors upon request.

6 Based on a Likelihood-Ratio test, the Null Hypothesis "all correlations are zero" can be rejected at $p<0.01\left(\chi^{2}(6)=439.74\right)$. 
Energyintensity turns out to be statistically significant (at $p<0.01$ ) for half the measures considered, i.e. switchoff and purchase, and takes on the expected positive sign. Thus, organizations which are more energy intensive are also more likely to switch off energy-using installations, and to consider energy efficiency for new purchases.

Similarly, while the parameter estimate associated with floorsize exhibits the expected positive sign, it is only statistically significant $(p<0.1)$ for lightoff. Organizations with larger buildings (in $\mathrm{m}^{2}$ ) need more lighting services. Thus, switching off lights when they are not needed is expected to lead to higher electricity cost services, ceteris paribus. The parameter estimate associated with employees is positive for three equations. Larger organizations are more likely $(p<0.01)$ to adopt energy management and controlling systems. Employees is not statistically significant for any other low-cost energy efficiency measures considered.

Rented is statistically significant and exhibits the expected negative sign in all four adoption equations, suggesting that the landlord-tenant dilemma also holds for low-cost energy efficiency measures. For interpretation, we calculate the estimates of the average marginal effects, taking into account the dichotomous character of rented. Accordingly, renting rather than owning decreases the probability of switching off energy-using installations whenever possible by 18 percentage points, the probability of switching off the lights by 11 percentage points, the probability of adopting management measures by 11 percentage points, and the probability of considering energy efficiency for new purchases by 14 percentage points.

For management and purchase, subsidiary exhibits a positive sign, and is also statistically significant (at $p<0.1$ and $p<0.01$, respectively). Implementation of energy management systems or requirements about purchasing procedures are likely be decided at the level of the mother organization, which then diffuses the relevant information and know-how to its subsidiaries.

The result for rural is rather mixed, and no clear pattern emerges: organizations in rural areas are more likely to switch off lights, but less likely to require energy efficiency to be required for new purchases.

Finally, only very few sector dummies are found to be statistically significant, namely hotels/restaurants for management and purchase, hospitals/schools/pools and food for management and officices for switchoff. Given sector heterogeneity, this is somewhat surprising. Thus, unlike for energy efficiency measures in general (e.g. Schleich 2009), for the low cost energy efficiency measures considered we find no support that differences across sectors have a strong effect on the adoption. 
Table 5: $\quad$ Results of multivariate probit model

\begin{tabular}{|c|c|c|c|c|}
\hline Explanatory variables & switchoff & lightoff & management & purchase \\
\hline \multirow[t]{2}{*}{ powerprice } & 0.892 & $2.336^{* *}$ & -0.671 & 0.119 \\
\hline & $(0.996)$ & $(1.056)$ & $(1.076)$ & $(1.021)$ \\
\hline \multirow[t]{2}{*}{ energyintensity } & $0.00745^{\star * *}$ & 0.00177 & -0.00232 & $0.00856^{* * *}$ \\
\hline & $(0.00264)$ & $(0.00166)$ & (0.00192) & $(0.00323)$ \\
\hline \multirow[t]{2}{*}{ floorsize } & 0.00643 & $0.0220^{*}$ & 0.0135 & 0.0108 \\
\hline & $(0.00994)$ & $(0.0120)$ & $(0.0163)$ & $(0.0157)$ \\
\hline \multirow[t]{2}{*}{ employees } & 0.587 & -1.074 & $11.01^{\star \star \star}$ & 1.224 \\
\hline & $(0.724)$ & $(0.661)$ & $(2.531)$ & $(1.156)$ \\
\hline \multirow[t]{2}{*}{ rented } & $-0.481^{\star \star \star}$ & $-0.342^{\star \star \star}$ & $-0.330^{\star \star \star}$ & $-0.388^{\star * *}$ \\
\hline & $(0.0756)$ & $(0.0793)$ & $(0.0787)$ & $(0.0770)$ \\
\hline \multirow[t]{2}{*}{ subsidiary } & -0.140 & -0.0608 & $0.157^{*}$ & $0.274^{\star \star *}$ \\
\hline & $(0.0877)$ & $(0.0938)$ & $(0.0909)$ & $(0.0920)$ \\
\hline \multirow[t]{2}{*}{ rural } & -0.0837 & $0.139^{*}$ & 0.0966 & $-0.390^{* * *}$ \\
\hline & $(0.0748)$ & $(0.0804)$ & $(0.0768)$ & $(0.0772)$ \\
\hline \multirow[t]{2}{*}{ construction } & 0.0954 & -0.103 & 0.101 & 0.309 \\
\hline & $(0.246)$ & $(0.277)$ & $(0.266)$ & $(0.250)$ \\
\hline \multirow[t]{2}{*}{ offices } & $0.389^{*}$ & 0.0341 & $0.437^{*}$ & 0.371 \\
\hline & $(0.228)$ & $(0.258)$ & $(0.249)$ & $(0.234)$ \\
\hline \multirow[t]{2}{*}{ small manufacturing } & 0.102 & -0.213 & 0.283 & 0.312 \\
\hline & $(0.241)$ & $(0.269)$ & $(0.260)$ & $(0.245)$ \\
\hline \multirow[t]{2}{*}{ retail trade } & 0.117 & -0.221 & 0.310 & 0.376 \\
\hline & $(0.227)$ & $(0.257)$ & $(0.250)$ & $(0.234)$ \\
\hline \multirow[t]{2}{*}{ hospitals/schools/pools } & 0.256 & 0.0777 & $0.700^{* *}$ & 0.359 \\
\hline & $(0.253)$ & $(0.287)$ & $(0.277)$ & $(0.259)$ \\
\hline \multirow[t]{2}{*}{ hotels/restaurants } & 0.323 & -0.209 & $0.652^{\star \star}$ & $0.534^{* *}$ \\
\hline & $(0.239)$ & $(0.265)$ & $(0.256)$ & $(0.244)$ \\
\hline \multirow[t]{2}{*}{ food } & 0.196 & -0.352 & 0.192 & $0.532^{\star *}$ \\
\hline & $(0.249)$ & $(0.280)$ & $(0.272)$ & $(0.262)$ \\
\hline \multirow[t]{2}{*}{ laundries } & 0.0502 & -0.354 & -0.408 & 0.0456 \\
\hline & $(0.372)$ & $(0.384)$ & $(0.439)$ & $(0.363)$ \\
\hline \multirow[t]{2}{*}{ agriculture } & 0.0349 & -0.0331 & -0.0911 & 0.173 \\
\hline & $(0.281)$ & $(0.319)$ & $(0.295)$ & $(0.286)$ \\
\hline \multirow[t]{2}{*}{ horticulture } & 0.190 & -0.653 & 0.150 & 0.271 \\
\hline & $(0.407)$ & $(0.435)$ & $(0.441)$ & $(0.431)$ \\
\hline \multirow[t]{2}{*}{ constant } & 0.0922 & 0.424 & $-0.649^{*}$ & 0.162 \\
\hline & $(0.315)$ & $(0.342)$ & $(0.349)$ & $(0.327)$ \\
\hline \multicolumn{5}{|c|}{ Wald $\left(\chi^{2}(68)=312.36\left(p>\chi^{2}=0\right)\right.$} \\
\hline$N$ & 1,528 & 1,528 & 1,528 & 1,528 \\
\hline
\end{tabular}




\section{Discussion and Conclusions}

In general, our empirical results suggest that most (but not all) the factors generally considered to drive adoption of high-cost energy efficient technologies in the tertiary sector also affect the adoption of low-cost measures such as switching off installations or lighting whenever possible, implementing measures to manage and control energy use, and routinely considering energy efficiency for new purchases.

In particular, we find that the landlord-tenant dilemma holds for the adoption of all the low-cost energy efficiency measures considered. These measures are often physically linked to the buildings infrastructure, such as automatic lighting systems or metering systems, and may thus qualify for the landlord-tenant dilemma. In this sense, our findings complement the existing literature, which finds the landlord-tenant problem to be a prevalent barrier to energy efficiency in residential buildings (see e.g. Ástmarsson et al. 2013), and for typically rather high cost energy efficiency measures in the tertiary sector (Schleich and Gruber 2008, Schleich 2009).

In comparison, our results for the effects of financial incentives are more diverse. Power prices (and also floor space) appear to matter for the take up of lighting measures only. Since the other measures considered may - in addition to electricity also involve fuel use, the electricity price may capture the financial incentives incompletely, only. Instead, we find that energy intensity, as measured by total electricity and fuel use per employee, is positively related to switching off installations when they are not needed, and to considering energy efficiency when making new purchases. Arguably, this finding reflects a higher strategic value of these measures than lighting measures or general energy management procedures. In essence though, our findings imply that financial incentives such as higher energy prices accelerate the diffusion of low-cost energy measures.

Our findings also hint, that knowledge transfer from the mother company to a subsidiary is a relevant factor, at least for the diffusion of energy management practices and for considering energy efficiency when purchasing new products (e.g. via formal provisions in procurement procedures), Thus, effective energy efficiency policy could specifically target mother companies.

Somewhat surprisingly, sectoral heterogeneity appears to have little impact on the adoption of low cost energy efficiency measures. Arguably, the hospitals, schools and pools, which include primarily public-sector organizations, may be more likely to adopt energy management measures because they are subject to higher external control. This control may be exerted indirectly by the general directly public, or directly via publicly elected council members in the governing boards. In general, results from 
other studies imply that the factors driving adoption of energy efficiency measures differ by sectors, though (e.g. Schleich and Gruber 2008, Schleich 2009). However, these studies explored measures requiring larger investments in energy-efficient technologies, while our analysis focuses on low-cost measures. In this sense, the findings of this paper do not provide empirical support for sector-specific policies to accelerate the diffusion of low-cost energy savings measures. For these measures generic policies may be more appropriate.

As a caveat we need to point out that our set of explanatory variables is unlikely to be be exhaustive, i.e. other factors, not included in our analysis, may affect the adoption of low-cost energy efficiency measures in the German tertiary sector. If these missing variables were correlated with the explanatory variables included in our analysis, our parameter estimates would be biased. For example, our analysis does not include a measure of capital availability, which was found to be an important factor for the adoption on energy efficiency measures in the literature. However, since we only consider low-cost measures, we do not believe this to cause problems. To properly assess the effect of factors like organizational culture on organizations' adoption behaviour, case study interviews may be more appropriate, since it is challenging to develop reliable scales which may be implemented in a large sample survey.

\section{Acknowledgements}

The survey on energy use in the German tertiary sector was sponsored by the German Federal Ministry of Economics and Technology. We would further like to thank Prof. Dr. Kornelis Blok and two anonymous reviewers for their helpful comments.

\section{Literature}

Abdelaziz, E.A., Saidura, R., Mekhilef, S.(20119: A review on energy saving strategies in the industrial sector. Renewable and Sustainable Energy Reviews 15 (1), 2011, 150-168.

AGEB (Arbeitsgemeinschaft Energiebilanzen - Working Group Energy Balances) (2013). Evaluation Tables on the Energy Balance for the Federal Republic of Germany 1990 to 2012 (as of 31 July 2013) and Preface to the Energy Balances. http://www.ag-energiebilanzen.de/EN/downloads/downloads.html

Aramyan, L. H., Lansink, A. G. J. M. O., \& Verstegen, J. A. A. M. (2007). Factors underlying the investment decision in energy-saving systems in Dutch horticulture. Agricultural Systems, 94(2), 520-527. 
Ástmarsson,B., Jensen, P.A., Maslesa, E. (2013). Sustainable renovation of residential buildings and the landlord/tenant dilemma, Energy Policy 63, 2013, pp. 355-362

Cagno, E.; Trucco, P.; Trianni, A.; Sala, G. (2010). Quick-E-scan: A methodology for the energy scan of SMEs. Energy, 35 (5), 2010, pp. 1916-1926.

Cooremans, C. (2011). Make it strategic! Financial investment logic is not enough. Energy Efficiency, 4(4), 473-492.

Dechezleprêtre, A., Glachant, M. Ménière Y. (2008). The clean development mechanism and the international diffusion of technologies: An empirical study. Energy Policy 36, 1273-1283.

Eichhammer, W. Analysis of a European Reference Target System for 2030 (2013). Report by Fraunhofer ISI for the Coalition for Energy Savings. Karlsruhe. http://energycoalition.eu/sites/default/files/Fraunhofer\%20ISI_ReferenceTargetSy stemReport.pdf.

Gruber, E., Brand, M. (1991). Promoting energy conservation in small and mediumsized companies. Energy Policy, 19(3), 279-287

Fleiter, T., Schleich, J. and Ravivanpong, P. (2012). Adoption of energy-efficiency measures in SMEs - An empirical analysis based on energy audit data from Germany. Energy Policy 51, 2012, 863-875. (http://dx.doi.org/10.1016/j.enpol.2012.09.041)

Fraunhofer ISI (2012). Concrete Paths of the European Union to the $2^{\circ} \mathrm{C}$ Scenario: Achieving the Climate Protection Targets of the EU by 2050 through Structural Change, Energy Savings and Energy Efficiency Technologies. Karlsruhe. http://www.isi.fraunhofer.de/isi-de/e/projekte/bmu_eu-energyroadmap_315192_ei.php.

Fraunhofer ISI, TU Vienna, PwC (2014): Study evaluating the current energy effi-ciency policy framework in the EU and providing orientation on policy options for realising the cost-effective energy-efficiency/saving potential until 2020 and beyond. Report on behalf of DG ENER. Karlsruhe, Vienna, Rome, 19 September 2014. http://ec.europa.eu/energy/efficiency/studies/efficiency_en.htm

Greene, W. H. (2012). Econometric analysis, Boston, London: Pearson

Gruber, E.; Brand, M. (1991). Promoting energy conservation in small and mediumsized companies. Energy Policy, 19 (3), pp. 279-287. 
IEA (International Energy Agency) (2013). World Energy Outlook 2013. OECD/IEA, Paris.

Jochem, E.; Gruber, E. (1990). Obstacles to rational electricity use and measures to alleviate them. Energy Policy, 18 (4), 1990, pp. 340-350.

Mills, B. and Schleich, J. (2012): Residential Energy-Efficient Technology Adoption, Energy Conservation, Knowledge, and Attitudes: An Analysis of European Countries. Energy Policy 49, pp. 616-628.

Mills, B. and Schleich, J. (2014): Household Transitions to Energy Efficient Lighting: Energy Economics, forthcoming.

Nagesha, N.; Balachandra, P. (2006). Barriers to energy efficiency in small industry clusters: Multi-criteria-based prioritization using the analytic hierarchy process. Energy 31 (12), pp. 1969-1983.

Nair, G; Gustavsson, L.; Mahapatra, K. (2010): Factors influencing energy efficiency investments in existing Swedish residential buildings. Energy Policy 38, pp. 2956-2963.

Ostertag, K. (2003). No-regret potentials in energy conservation: An analysis of their relevance, size and determinants. Physica: Heidelberg.

Palm, J. (2009). Placing barriers to industrial energy efficiency in a social context: a discussion of lifestyle categorisation. Energy Efficiency, 2(3): 263-270.

Rogers, E. M. (2003). Diffusion of Innovations, 5th Edition. Simon and Schuster.

Sardianou, E. (2007). Estimating energy conservation patterns of Greek households. Energy Policy 35, pp. 3778-3791;

Schleich, J. (2004). Do energy audits help reduce barriers to energy efficiency? An empirical analysis for Germany. International Journal of Energy Technology and Policy, 2(3):226-239

Schleich, J.; Gruber, E. (2008). Beyond case studies: barriers to energy efficiency in commerce and the services sector. Energy Economics, 30 (2), 2008, pp. 449464.

Schleich, J. (2009). Barriers to energy efficiency: a comparison across the German commercial and services sector. Ecological Economics, 68 (7), 2009, pp. 21502159. 
Schlomann, B., Steinbach, J., Kleeberger, H., Geiger, B., Pich, A., Gruber, E., Mai, M., Gerspacher, A., Schiller, W (2013). Energy consumption of the tertiary sector (trade, commerce and services) for the years 2007 to 2010. Summary Report to the Federal Ministry of Economics and Technology (BMWi). Karlsruhe, Munich, Nuremberg: Fraunhofer ISI.

Schlomann, B., Gruber, E., Geiger, B., Kleeberger, (Ed.) (2014). Energieverbrauch des Sektors Gewerbe, Handel, Dienstleistungen (GHD) in Deutschland für die Jahre 2006 bis 2011. Stuttgart: Fraunhofer Verlag. ISBN 978-3-8396-0691-9

Sorrell, S.; O’Malley, E.; Schleich, J.; Scott, S. (2004). The economics of energy efficiency. Cheltenham, Elgar.

Stenqvist, C., Nilsson, L. J., Ericsson K., Modig, G. (2011). Energy management in the Swedish pulp and paper industry - the daily grind that matters. Proceedings of the ECEEE 2011 Summer Study, 3, 2011 767-776.

Stenqvist, C. (2012). Evaluating industrial energy management systems considerations for an evaluation plan. Proceedings of the 2012 International Energy Program Evaluation Conference (IEPEC), 12-14 June 2012, Rome.

Stenqvist, C.; Nilsson, L. (2012). Energy efficiency in energy-intensive industries - an evaluation of the Swedish voluntary agreement PFE. Energy Efficiency, 5 (2), 2012, pp. 225-241.

Thollander, P, Danestig, M., \& Rohdin, P. (2007). Energy policies for increased industrial energy efficiency: Evaluation of a local energy programme for manufacturing SMEs. Energy Policy, 35(11), 57743):226

Thollander, P., Ottosson, M. (2010). Energy management practices in Swedish energyintensive industries. Journal of Cleaner Production, 18(12), 2010, 1125-1133.

Thollander, P.; Dotzauer, E. (2010). An energy efficiency program for Swedish industrial small- and medium-sized enterprises. Journal of Cleaner Production, 18 (13), 2010, 1339-1346.

Trianni, A., Cagno, E. (2012). Dealing with barriers to energy efficiency and SMEs: Some empirical evidences. Energy, 37(1), 494-504

Trianni, A., Cagno, E., and Worrell, E. (2013). Innovation and adoption of energy efficient technologies: An exploratory analysis of Italian primary metal manufacturing SMEs. Energy Policy, 61(C), 430-440. 
Velthuijsen, J. 1993. Incentives for investment in energy efficiency: an econometric evaluation and policy implications. Environmental and resource economics, 3. (2), pp. 153-169. 


\section{Appendix A}

Results of the univariate probit model appear in Table A.1. The parameters are estimated via maximum likelihood, hetoreskedasticity robust standard errors are reported in parentheses below the parameter estimates. 
Table A.1: $\quad$ Results of univariate probit models

\begin{tabular}{|c|c|c|c|c|}
\hline Explanatory variables & switchoff & lightoff & management & purchase \\
\hline \multirow[t]{2}{*}{ powerprice } & 0.880 & $2.196^{* *}$ & -0.669 & -0.152 \\
\hline & $(1.000)$ & $(1.050)$ & $(1.090)$ & $(1.024)$ \\
\hline \multirow[t]{2}{*}{ energyintensity } & $0.00701^{* * *}$ & 0.00135 & -0.00262 & $0.00850^{* * *}$ \\
\hline & $(0.00261)$ & $(0.00146)$ & $(0.00220)$ & $(0.00321)$ \\
\hline \multirow[t]{2}{*}{ floorsize } & 0.00756 & 0.0214 & 0.0134 & 0.0129 \\
\hline & $(0.0103)$ & $(0.0133)$ & $(0.0166)$ & $(0.0159)$ \\
\hline \multirow[t]{2}{*}{ employees } & 0.493 & -1.153 & $11.19^{\star \star \star}$ & 0.787 \\
\hline & $(0.778)$ & $(0.729)$ & $(2.584)$ & $(1.113)$ \\
\hline \multirow[t]{2}{*}{ rented } & $-0.487^{\star * *}$ & $-0.352^{* * *}$ & $-0.340^{* * *}$ & $-0.395^{\star * *}$ \\
\hline & $(0.0759)$ & $(0.0798)$ & $(0.0794)$ & $(0.0771)$ \\
\hline \multirow[t]{2}{*}{ subsidiary } & $-0.150^{*}$ & -0.0562 & $0.151^{*}$ & $0.256^{\star \star *}$ \\
\hline & $(0.0884)$ & $(0.0943)$ & $(0.0918)$ & $(0.0923)$ \\
\hline \multirow[t]{2}{*}{ rural } & -0.0947 & $0.138^{*}$ & 0.0906 & $-0.402^{* * *}$ \\
\hline & $(0.0751)$ & $(0.0809)$ & $(0.0772)$ & $(0.0768)$ \\
\hline \multirow[t]{2}{*}{ construction } & 0.106 & -0.0931 & 0.0814 & 0.292 \\
\hline & $(0.240)$ & $(0.269)$ & $(0.264)$ & $(0.242)$ \\
\hline \multirow[t]{2}{*}{ offices } & $0.375^{\star}$ & 0.0931 & $0.417^{\star}$ & 0.344 \\
\hline & $(0.222)$ & $(0.251)$ & $(0.245)$ & $(0.224)$ \\
\hline \multirow[t]{2}{*}{ small manufacturing } & 0.0983 & -0.161 & 0.258 & 0.283 \\
\hline & $(0.235)$ & $(0.262)$ & $(0.258)$ & $(0.236)$ \\
\hline \multirow[t]{2}{*}{ retail trade } & 0.133 & -0.170 & 0.297 & $0.374^{*}$ \\
\hline & $(0.222)$ & $(0.249)$ & $(0.246)$ & $(0.224)$ \\
\hline \multirow[t]{2}{*}{ hospitals/schools/pools } & 0.239 & 0.128 & $0.694^{\star *}$ & 0.332 \\
\hline & $(0.244)$ & $(0.280)$ & $(0.274)$ & $(0.248)$ \\
\hline \multirow[t]{2}{*}{ hotels/restaurants } & 0.307 & -0.170 & $0.634^{\star *}$ & $0.495^{\star *}$ \\
\hline & $(0.232)$ & $(0.257)$ & $(0.253)$ & $(0.234)$ \\
\hline \multirow[t]{2}{*}{ food } & 0.218 & -0.299 & 0.183 & $0.526^{* *}$ \\
\hline & $(0.247)$ & $(0.273)$ & $(0.269)$ & $(0.253)$ \\
\hline \multirow[t]{2}{*}{ laundries } & 0.0982 & -0.324 & -0.420 & 0.0570 \\
\hline & $(0.363)$ & $(0.373)$ & $(0.438)$ & $(0.365)$ \\
\hline \multirow[t]{2}{*}{ agriculture } & 0.0237 & -0.0697 & -0.124 & 0.115 \\
\hline & $(0.275)$ & $(0.309)$ & $(0.295)$ & $(0.277)$ \\
\hline \multirow[t]{2}{*}{ horticulture } & 0.227 & -0.613 & 0.148 & 0.325 \\
\hline & $(0.407)$ & $(0.418)$ & $(0.438)$ & $(0.425)$ \\
\hline \multirow[t]{2}{*}{ constant } & 0.0935 & 0.421 & $-0.628^{*}$ & 0.249 \\
\hline & $(0.312)$ & $(0.337)$ & $(0.350)$ & $(0.322)$ \\
\hline Wald $\left(\chi^{2}(16)\right.$ & 80.71 & 57.76 & 133.87 & 82.35 \\
\hline$p>\chi^{2}$ & 0.00 & 0.00 & 0.00 & 0.00 \\
\hline Pseudo $R^{2}$ & 0.041 & 0.033 & 0.108 & 0.044 \\
\hline$N$ & 1,528 & 1,528 & 1,528 & 1,528 \\
\hline
\end{tabular}

Note: ${ }^{\star \star *}$ indicates significance at $\mathrm{p}<0.01,{ }^{* \star}$ indicates significance at $\mathrm{p}<0.05$ and * indicates significance at $p<0.1$ in an individual two-tailed $z$-test 